\title{
EFFECT OF MARATHON TRAINING ON THE PLASMA LACTATE RESPONSE TO SUBMAXIMAL EXERCISE IN MIDDLE-AGED MEN
}

\author{
A. G. RUMLEY, R. TAYLOR*, S. GRANTt, A. R. PETTIGREW, I. FINDLAY $\ddagger$ and H. DARGIE \\ Departments of Pathological Biochemistry and $¥$ Cardiology, Western Infirmary, Glasgow \\ *Institute of Physiology and +Dept. of Physical Education, University of Glasgow
}

\begin{abstract}
Twenty-one previously sedentary male volunteers (aged 35-50 years) undertook a defined marathon training programme lasting 30 weeks. At weeks 0 (T1), 15 (T2) and 30 (T3) they underwent measurement of maximal oxygen uptake (VO $\mathrm{max}_{2}$, submaximal $\mathrm{VO}_{2}$ and submaximal plasma lactate concentration during cycle ergometry. No exercise was taken for 24-48 hours prior to testing. During training aerobic power increased significantly $(\mathrm{p}<0.001)$ from an initial $\mathrm{VO}_{2} \mathrm{max}$ at $\mathrm{T}_{1}$ of

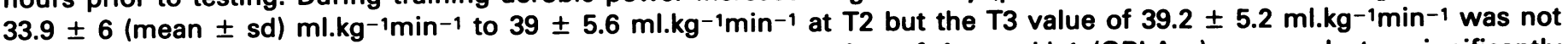
significantly different from that at T2. Plasma lactate concentration of $4 \mathrm{mmol} . \mathrm{I}^{-1}$ (OBLAw) occurred at a significantly $(P<0.05)$ higher workload $(155 \pm 28 \mathrm{w})$ at $\mathrm{T} 2$ compared with $\mathrm{T} 1(132 \pm 30 \mathrm{w})$ but the T3 figure was $137 \pm 34 \mathrm{w}$. OBLA VO $\mathrm{OB}_{2}$ at T1 was $2.04 \pm 0.42$ I. $\mathrm{min}^{-1}$, at T2 was $2.24 \pm 0.04$ I.min-1 but at T3 was $2.03 \pm 0.30$ I. $\mathrm{min}^{-1}$ (T1:T2 P < 0.05, T1:T3 NS). OBLA $\% \mathrm{VO}_{2}$ max at $\mathrm{T} 1$ was $75 \pm 12 \%$, at $\mathrm{T} 2$ was $73 \pm 11 \%$ but at T3 was $62 \pm 10 \%$ (T1:T2 NS, T1:T3 P<0.01).

Key words: Plasma lactate, Submaximal exercise, Marathon training
\end{abstract}

\section{INTRODUCTION}

It has been demonstrated that the maximum oxygen uptake $\left(\mathrm{VO}_{2}\right.$ max), increases to a plateau during training and does not increase further during the later stages of a training programme despite an increase in running performance (as assessed by pace and distance during training) and it has been proposed that this pattern of change reflects the fact that aerobic power is not the only determinant of endurance capacity (Pollock, 1972). It has also been suggested that metabolic parameters measured during submaximal exercise may be better indicators of endurance (Daniels et al, 1978; Katch et al, 1978; Kinderman et al, 1979). For this reason the plasma lactate response during an exercise test was investigated in our subjects to monitor the effect of a marathon training programme on indicators of endurance capacity.

In this study we examined the effect of training both with regard to range of plasma lactate response from rest to peak exercise and with regard to the onset of plasma lactate accumulation OPLA in a group of previously sedentary middle-aged men.

\section{METHODS}

The subjects studied were 35 middle-aged men (35-50 years) who had been recruited through a newspaper advertisement to partcipate in a study of the effects of a marathon training programme on cardiological, physiological and biochemical indices of physical fitness and risk factors for coronary heart disease. These men had previously taken no regular exercise, were not being treated for any medical condition and had not run a marathon race before the study commenced. Of the original 35 recruits 8 dropped out during the study due to injury, lack of interest or other reasons and 27 carried out the full training programme. Analytical problems and incomplete test attendances impaired 6 sets of results, so that 21 full sets were ultimately obtained.

The prescribed training programme lasted 30 weeks and

Address for correspondence:

A. G. Rumley, MSc, MCB

Dept. of Pathological Biochemistry

Western Infirmary

Glasgow G11 6NT increased in stages from an initial 3 runs of 20 min each per week (60 $\mathrm{min} /$ week) to a peak at 28 weeks in which there was a lonig run on one day of 3 hours and on 5 other days runs of 40 to $90 \mathrm{~min}$ ( $8 \mathrm{~h} /$ week) with at least one day of rest per week throughout. A further two weeks of training at a much lower level of effort was followed by the Glasgow marathon in week 31. An attempt was made to monitor the intensity of effort during the training by measuring heart rate using portable equipment (Sport Tester PE 2000 pulse rate monitor. Polar Electro KY, Finland) which the subjects could carry whilst running. A sample of 5 runners were monitored in this way, the small number being dictated by the availability of equipment.

Testing of the subjects was carried out at weeks 0,15 and 30 (T1, T2 and T3 respectively) and they refrained from training on the day prior to testing. At each testing stage the subjects undertook a maximal exercise test on a cycle ergometer following a standard protocol during which the pedalling resistance was increased from $75 \mathrm{w}$ initially in steps of $25 \mathrm{w}$ at $3 \mathrm{~min}$ intervals whilst maintaining a constant pedalling speed of 50 rev. $\mathrm{min}^{-1}$; the test was continued until exhaustion.

Blood samples were taken at rest, at the end of each 3 minute period and finally at exhaustion, through an indwelling cannula in an antecubital vein into fluoride/ oxalate preservative. Plasma from these samples was stored at $-20^{\circ} \mathrm{C}$ until analysis. Lactate concentration was measured using a fully enzymatic, U.V. spectrophotometric assay (Boehringer, Mannheim).

Oxygen uptake was assessed during the final minute of the 3 minute period at each workload and during the last 60 seconds of effort before exhaustion, using the Douglas bag method. In some instances it was not possible for subjects to sustain maximal effort for one minute and a $\mathbf{3 0}$ second sample was taken. Oxygen and carbon dioxide content was assessed using paramagnetic (Servomex) and infra-red analysers (P. K. Morgan) previously calibrated with gas mixtures standardised by Lloyd-Haldane analysis. Volume of expired air was measured using a calibrated Parkinson Cowan dry gas meter.

Cardiac function was monitored on all subjects throughout the test using an electrocardiograph (ECG). The significance of the observed changes was assessed using Student's paired ' $t$ ' test. 


\section{RESULTS}

Maximal oxygen uptake increased significantly $(P<0.001)$ from pre-training levels of $2.7 \pm 0.52 \mathrm{I}_{\mathrm{min}} \mathrm{mi}^{-1}$ (33.9 \pm 6.0 $\left.\mathrm{ml} . \mathrm{kg}^{-1} \mathrm{~min}^{-1}\right)$ to 15 week levels of $2.99 \pm 0.42$ l.min-1 $\left(39.0 \pm 5.6 \mathrm{ml} \mathrm{kg}^{-1} \mathrm{~min}^{-1}\right)$ but from 15 weeks to 30 weeks $\left(2.91 \pm 0.37 \mathrm{l} . \mathrm{min}^{-1}, 39.2 \pm 5.2 \mathrm{ml}^{2} \mathrm{~kg}^{-1} \mathrm{~min}^{-1}\right)$ this increase was not significant.

Plasma lactate concentrations at the same submaximal work rate were lower both at T2 and T3 (Fig. 1) however the trend from T1 to T2 was reversed at T3. The difference between the work load corresponding to a lactate concentration of $4 \mathrm{mmol}^{-1-1}$ (OPLA $w$ ) at T1 and T2 was significant $(P<0.05)$ but not significant between $T 1$ and $T 3$. The data corresponding to plasma lactate concentration of $4 \mathrm{mmol} . \mathrm{I}^{-1}$ are summarised in Table II. When lactate concentration was plotted against oxygen consumption (Fig. 2) there was a tendency for a lower lactate concentration to occur at a given submaximal $\mathrm{VO}_{2}$ at $\mathrm{T} 2$ compared to $\mathrm{T} 1$. However at T3 this pattern was reversed and a higher lactate concentration was apparent at a given $\mathrm{VO}_{2}$ than at T1. At the $4 \mathrm{mmol}^{-\mathrm{I}^{-1}}$ lactate concentration was apparent at a given $\mathrm{VO}_{2}$ than at T1. At the $4 \mathrm{mmol} . \mathrm{I}^{-1}$ lactate concentration (OPLA VO V $_{2}$ ) the difference between T1 and T2 was significant $(P<0.05)$ but that between $T 1$ and $T 3$ was not significant.

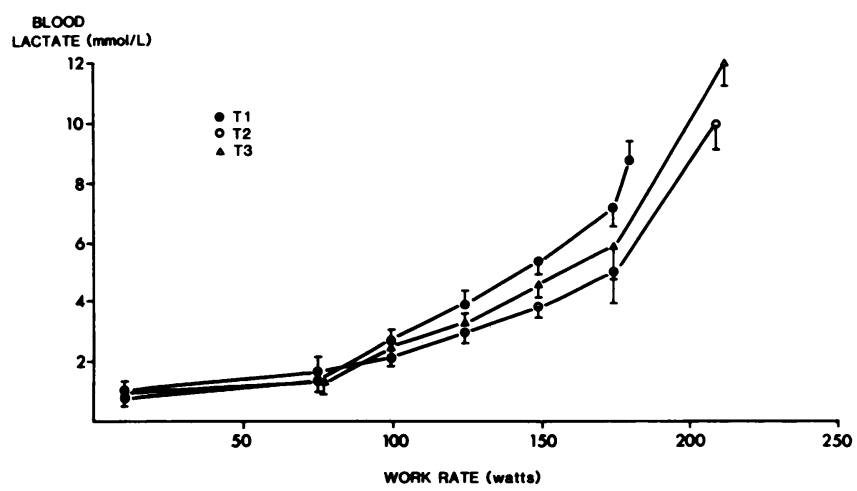

Fig. 1: Plasma lactate concentration at each work rate at 0 weeks (T1) 15 weeks (T2) and 30 weeks (T3) training (mean and SEM, $n=21$ ).

TABLE II

Physiological responses at the exercise intensity corresponding to OPLA (mean \pm sd) $n=12$

\begin{tabular}{lccc}
\hline & $\begin{array}{c}\text { Week 0 } \\
\text { (T1) }\end{array}$ & $\begin{array}{c}\text { Week 15 } \\
\text { (T2) }\end{array}$ & $\begin{array}{c}\text { Week 30 } \\
\text { (T3) }\end{array}$ \\
\hline OPLA watts & $132 \pm 30$ & $155 \pm 28$ & $137 \pm 34$ \\
OPLA VO ${ }_{2} 1$. min $^{-1}$ & $2.04 \pm 0.42$ & $2.24 \pm 0.40$ & $2.03 \pm 0.30$ \\
OPLA \% $\mathrm{VO}_{2}$ max & $75 \pm 12$ & $73 \pm 11$ & $62 \pm 10$ \\
\hline
\end{tabular}

Fig. 4 demonstrates that there was a fall in oxygen uptake at a given work rate at $\mathrm{T} 2$ and $\mathrm{T} 3$. This fall in $\mathrm{VO}_{2}$ accounts for the apparent discrepancy in training response as assessed by OPLAw and OPLA $\mathrm{VO}_{2}$. When lactate concentration was plotted against percentage of maximal oxygen uptake (Fig. 3) higher lactate concentrations at a given $\% \mathrm{VO}_{2} \max$ (relative exercise intensity) occurred at both T2 and T3. At the $4 \mathrm{mmol}^{-\mathrm{I}^{-1}}$ lactate concentration the difference between $T 1$ and $T 2$ was not significant but the difference between $T 1$ and $T 3$ was significant $(P<0.01)$. The

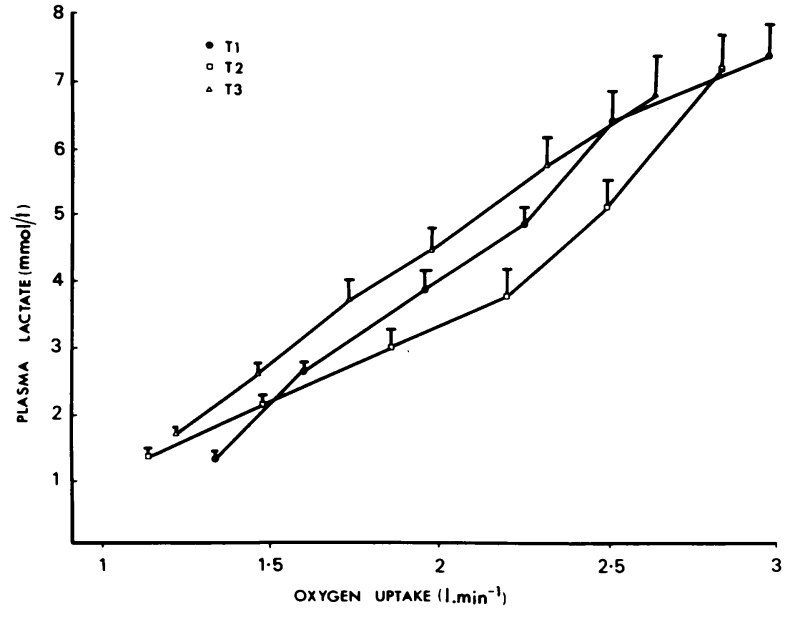

Fig. 2: Plasma lactate concentration vs. oxygen uptake at 0 weeks (T1) 15 weeks (T2) and 30 weeks (T3) training (mean and SEM, $n=21$ ).

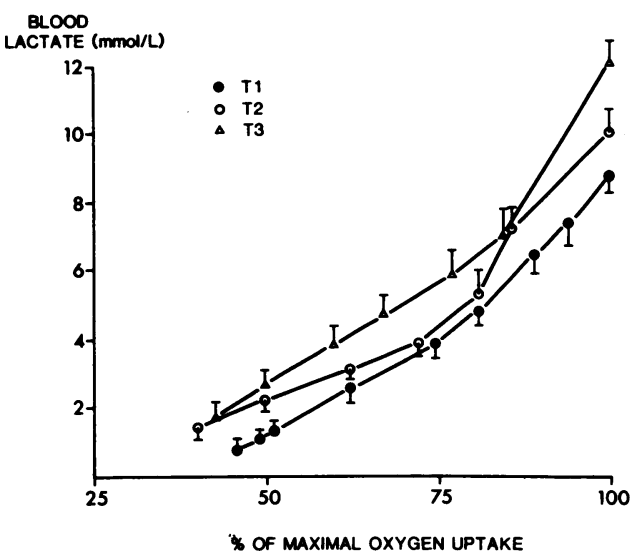

Fig. 3: Plasma lactate concentration vs. percentage of maximal oxygen consumption at $O$ weeks (T1) 15 weeks (T2) and 30 weeks (T3) training. (Mean and SEM, $n=21$.

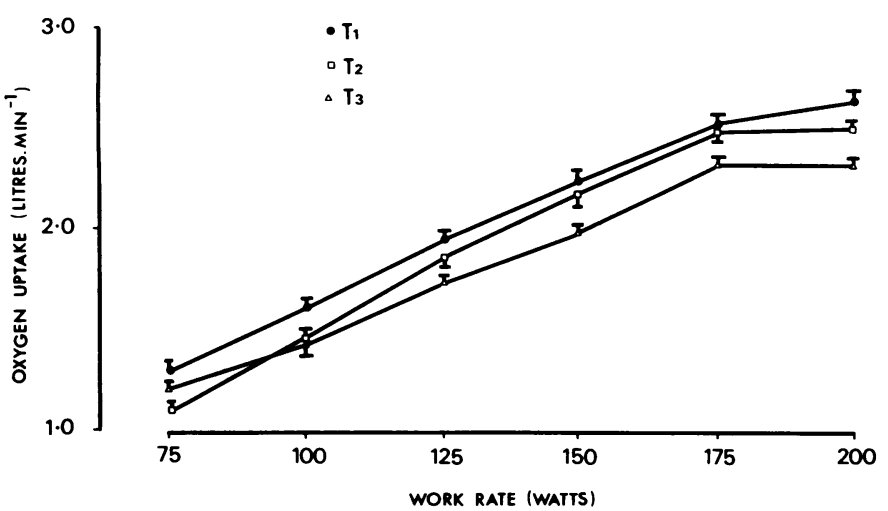

Fig. 4: Oxygen uptake vs. work-rate at T1 (0 weeks), T2 (15 weeks) and T3 (30 weeks) training (mean and SEM, $n=21$ ).

actual distances, times and intensities (\% of max heart rate) achieved during training are summarised in Table I. The data show that the exercise intensity did not fall below $88 \%$ of maximum heart rate throughout training in the 5 subjects monitored. The high value reflects the fact that monitoring was only carried out during short duration ( $<60 \mathrm{~min}$ ) effort. The mean finishing time for the marathon was 256 min with a range of 206-327 min. Only one subject failed to complete the race, dropping out through injury at 10 miles. 
TABLE I

Summary of the running training programme. Mean \pm sd

\begin{tabular}{|c|c|c|c|}
\hline & $\begin{array}{c}0-15 \\
\text { (T1-T2) }\end{array}$ & $\begin{array}{c}\text { Week } \\
15-30 \\
\text { (T2-T3) }\end{array}$ & $\begin{array}{c}1-30 \\
\text { (T1-T2) }\end{array}$ \\
\hline Distance run (miles) $n=21$ & $209 \pm 88$ & $434 \pm 126$ & $644 \pm 160$ \\
\hline Time run $(\min ) n=21$ & $1742 \pm 641$ & $3836 \pm 1193$ & $5578 \pm 1193$ \\
\hline $\begin{array}{l}\text { Percentage of maximum } \\
\text { heart rate, } n=5\end{array}$ & $91 \pm 5$ & $88 \pm 3$ & $90 \pm 4$ \\
\hline
\end{tabular}

\section{DISCUSSION}

The mode of testing of the subjects was not ideal since the mode of training was running, and $\mathrm{VO}_{2}$ max values determined during cycling exercise are likely to be rather lower than those determined during running (by about $8 \%$, Astrand and Rodahl, 1977). This compromise was chosen because cardiac ventriculography, which requires a stationary subject, was also carried out during the exercise test (results published elsewhere, Findlay et al, 1986). However, despite the non-specificity of the mode of exercise testing the $\mathrm{VO}_{2}$ max results show that it is valid for demonstrating improvements in aerobic capacity in this study. Training appeared to modify the submaximal exercise plasma lactate response although the pattern of change was not the same after 30 weeks as after 15 weeks. After 15 weeks a fall in plasma lactate concentration was observed at a given submaximal work-rate and at a given oxygen uptake. This reduction is in agreement with other training studies in middle-aged men (Saltin et al, 1969; Ekblöm et al, 1968). OPLA was achieved on average at $17 \%$ and $15 \%$ higher values of work-rate and oxygen uptake respectively. This improvement in OPLA also agrees with previous studies in this age group (Denis et al, 1984; Hollman, 1961). In contrast to the lowering of submaximal plasma lactate concentrations after 15 weeks training and despite the maintenance of the improvement in $\mathrm{VO}_{2} \max$, a reversal of the measured lactate response occurred during the second 15 weeks of training. At 30 weeks the lactate concentration at a given submaximal work-rate was much the same as the pre-training level while the lactate concentration was higher at a given $\mathrm{VO}_{2}$ and relative intensity $\left(\% \mathrm{VO}_{2}\right.$ max $)$. There are several possible explanations for this reversal in plasma lactate response. A number of factors may be responsible for the increased lactate concentration at submaximal workloads: increased environmental temperature during testing (Bergh et al, 1986), detraining in response to a period of rest (Davis et al, 1976) and increased resting lactate concentration before testing, but none of these factors appeared to have been involved in our subject's response during testing.

In the absence of information about dietary carbohydrate intake the possibility that plasma lactate was elevated due to increased muscle glycogen stores cannot be discounted. It should be noted that a fairly normal mixed diet (i.e. $55 \%$ carbohydrate), allied to 24-48 hours rest, after prolonged endurance training can lead to an increase in muscle glycogen concentration (Costill et al, 1971). Subjects complied with the request to abstain from training in the $\mathbf{2 4}$ hours prior to testing.

Intensity of training is important in submaximal exercise lactate response. Training at $70 \% \mathrm{VO}_{2} \max$ is effective in lowering the plasma lactate response while training at $40 \%$
$\mathrm{VO}_{2}$ max is not (Sady et al, 1980). On the basis of the overload principle it has been suggested that high intensity exercise (at $70 \% \mathrm{VO}_{2}$ max or more) is necessary to "stress" the lactate production and thus result in adaptation (Wasserman et al, 1967). Others suggest that a training intensity that would produce a plasma lactate concentration of $4 \mathrm{mmol}^{-\mathrm{I}^{-1}}$ is optimal for eliciting a reduction in plasma lactate concentration at submaximal work-rates (Hollman, 1961; Kinderman et al, 1979; Mader et al, 1976). The plasma lactate concentration was not monitored in our subjects during training but the five runners who were monitored for training intensity were selected randomly and therefore thought to be representative of the group as a whole. Thus it appears unlikely that changes in the intensity of training could account for the reversal in plasma lactate response.

Glycogen depletion has been shown to affect the plasma lactate response to exercise. Hermansen and co-workers observed that repeated bouts of high intensity exercise $\left(77 \% \mathrm{VO}_{2}\right.$ max) resulted in a reduced plasma lactate response to given workloads, and intensities (Hermansen et al, 1967). Such exercise depletes the glycogen content, as judged by PAS staining, in fibres of type I, Ila and Ilb alike (Essen, 1978). However little experimental evidence has been presented with regard to the effect of continuous lower intensity exercise such as that of the present study training programme.

According to the size principle (Heinemann, 1980) it is the smaller type I fibres that are initially recruited during progressive exercise. Thus the type I and their slightly larger type lla counterparts would be expected to be recruited during lower intensity continuous exercise and therefore become depleted first. This specific pattern of glycogen depletion would result in an early recruitment of type IIb fibres during the exercise test thereby increasing the plasma lactate concentration.

In conclusion, it does appear that marathon training in novice middle-aged runners results in substantial improvement in maximal aerobic power and reduction of the plasma lactate response to exercise. This finding has not previously been demonstrated in this category of subjects with marathon training. The reversal of the lactate response during testing at the end of the training programme is an interesting observation which has not previously been reported. In reviewing the literature on this subject we find that very few of the published papers give details of the period of rest allowed before testing even though this information is important for the proper interpretation of the results of this type of study.

\section{ACKNOWLEDGEMENT}

We would like to acknowledge Dr. Neil Spurway and Dr. Bertil Sjødin for their constructive criticism during the preparation of this paper.

\section{References}

Astrand, P. O. and Rodahl, K., 1977. Textbook of work physiology. Publ. Mc-Graw Hill Book Company.

Bergh, U., Danielsson, U., Wennberg, L. and Sjødin, B., 1986 "Plasma Lactate and perceived exertion during heat stress". Acta Physiol.Scand. 126: 617-618.

Costill, D. L., Bowers, R. W., Branam, G. and Sparks, K., 1971 “Muscle glycogen utilisation during prolonged exercise on successive days". J.Appl.Physiol. 31: 834-838.

Daniels, H. T., Yarbrough, R. A. and Forster, C., 1978 "Changes in VO $\max _{2}$ and running performance with training". Eur.J.Appl.Physiol. 39: 249-254. Davis, J. A., Vodak, P., Wilmore, J. H., Vodak, J. and Kurtz, P., 1976 
"Anaerobic threshold and maximal aerobic power for three modes of exercise". J.Appl.Physiol. 41: 544-550.

Denis, C., Dormois, D. and Lacour, J. R., 1984 "Endurance training, $\nabla_{2}$ max and OBLA: A longitudinal study of two different age groups". Int.J.Sports Med. 5: 167-173.

Ekblöm, B., Åstrand, P. O., Saltin, B., Stenberg, J. and Walstrom, B., 1968 "Effect of training on circulatory response to exercise". J.Appl.Physiol. 4: 518-528.

Essen, B., 1978 "Studies on the regulation of metabolism in human skeletal muscle using intermittent exercise as an experimental model". Acta Physiol.Scand.Suppl. 454: 1032.

Findlay, I., Dargie, H., Cleland, J., Elliot, A., Fisher, M., Gillen, G. Henderson, E., Wilson, J., Taylor, R., Durnin, J., Grant, S., Manzie, A. Pettigrew, A., Rumley, A. and Percy-Robb, I., 1986 "A preliminary analysis of the cardiovascular effects of training for a marathon in middle-aged men". In: Sports in Medicine. Proceedings of the 8th Commonwealth International Conference on Sport. Glasgow 1986. Eds. J. A. McGregor and J. Moncur. Publ. E. and F. N. Spon, London and New York.

Heineman, E., 1980 "Organisation of the motoneurone pool: the size principle". In: Medical Physiology 14th Edition pp 718-741. Ed. V. B. Mountcastle. Publ. C. V. Mosby Co.

Hermansen, L., Hultman, E. and Saltin, B., 1967 “Muscle glycogen during prolonged severe exercise". Acta Physiol.Scand. 71: 129-139.
Hollman, W., 1961 "Zur Frage der Danerleistungfahigbeit". Forlsch.Med. 79: 439-453.

Katch, V., Weltman, A., Sady, S. and Fredson, P., 1978 "Validity of the relative percent concept for equating training intensity". Eur.J.Appl.Physiol. 39: 219-237.

Kinderman, W., Simon, G. and Keul, J., 1979 "The significance of the aerobicanaerobic transition for the determination of workload intensities during endurance training". Eur.J.Appl.Physiol. 42: 25-34.

Mader, A., Leissen, H., Heck, H., Phillipi, A., Rost, R., Schurch, P. and Hollman W., 1976 "Zur Beurteilung der Sportartspezitischen Ausdauerleistungfahigheit in Labor". Sportartzt.Sportmed. 27: 80-88.

Pollock, M. L., 1972 "The quantification of endurance training programmes". In: Exercise and Sport Science Reviews Vol. 1. Academic Press, New York. Ed. J. Wilmore. pp. 155-188.

Sady, S., Katch, V., Freedson, P. and Weltman, A., 1980 "Changes in metabolic acidosis: evidence for an intensity threshold". J.Sports Med. Phys. Fitness 20: 41-46.

Saltin, B., Hartley, H., Kilbom, A. and Åstrand, I., 1969 "Physical training in sedentary middle aged and older men. II Oxygen uptake, heart rate and blood lactate concentration at submaximal and maximal exercise". Scand.J.Clin.Invest. 24: 323-334.

Wasserman, K., Van Kessel, A. and Burton, E., 1967 "Interaction of physiological mechanisms during exercise". J.Appl.Physiol. 22: 71-85. 